\title{
O MOVIMENTO HUMANO
}

\author{
Valdir Barbanti*
}

\section{RESUMO}

A descrição da natureza do movimento humano revela sua complexidade desde os primeiros momentos da vida. $O$ homem na sua constante batalha com o meio ambiente é o mais despreparado para se locomover, porém é a única criatura que conseguiu se adaptar a todos os ambientes. O comportamento do movimento humano depende de caracteristicas genéticas e de fatores só-

Um dos fenômenos mais complexos associado ao ser humano é a maneira pela qual ele se move em seu meio ambiente. Do ponto de vista mecânico o movimento pode ser definido como a mudança de posição ou dos segmentos corporais no espaço e no tempo através da aplicação de vários graus de fôrça. $\mathrm{Pa}$ rece fácil entender o movimento com uma mera definição. Mas, a complexidade do movimento exige outras consideraçōes pela simples razão de que o movimento é o ingrediente básico de todo o ser vivo.

O movimento de um organismo em crescimento é um dos primeiros sinais de vida: ele é detectado já no estágio embrionário do desenvolvimento no útero materno e tem sido claramente identificado no estágio fetal do crescimento. cio-culturais. Um comportamento do movimento particular, o esportivo, depende de cadeias cinéticas e cadeias de freios que se alternam a cada mudança de posição no espaço. A compreensão dessas cadeias cinéticas traz como conseqüência diretrizes para treinar a efetividade dos movimentos.

Os padrōes ordenados de crescimento no bebê são caracterizados por sua capacidade progressiva de se mover. Um dos momentos de mais orgulho na vida dos pais é quando o bebê dá os primeiros passos, porque mostra a evidência que a criança está progredindo normalmente na aquisição de habilidades motoras que caracterizam a espécie humana.

Embora o Homem não possa correr tão rápido quanto um quadrúpede; nadar tāo bem quanto um golfinho; ou voar como um pássaro, ele é o ser vivo de maior sucesso na luta com seu meio ambiente; no desafio da fôrça de gravidade: e de se movimentar no espaço extraterreno.

Um dos fatôres fundamentais que possibilita ao Homem realizar tais feitos é a característica de se movimentar no seu meio ambiente

\footnotetext{
* Professor Assistente Doutor do Departamento Técnico Desportivo da EEFUSP
} 
em duas pernas. Com as mãos livres para manipular objetos e materiais de seu mundo, e ainda pela vantagem do polegar oposto aos dedos, ele se tornou um modelador de instrumentos, um manipulador de seu meio ambiente, um explorador e um criador. De acôrdo com alguns antropologistas foram esses fatos que permitiram ao seu cérebro ter o tamanho e a complexidade atual.

O principal meio de locomoção do Homem ainda é suas duas pernas, mesmo que seja apenas para andar até o carro ou ao ponto de ônibus. Em uma sociedade automatizada como a nossa, o trabalho e as viagens com cada vez menos esforço físico para o individuo trouxe muitos benefícios. Desafortunadamente, há certos efeitos colaterais que nāo trazem vantagens. Entre eles estāo as chamadas doenças hipocinéticas, causadas em grande parte pela falta de atividade física vigorosa, regular.

A estrutura física permite ao Homem se movimentar de muitas formas, mas as leis físicas colocam certas restriçōes nesta movimentação. Por exemplo, desde cedo aprendemos, quando damos os primeiros passos, que "tudo que sobe, desce" e muitos aprendem a apreciar esta luta contra o meio ambiente e persistem, até que se possa correr mais rápido, chutar com mais precisāo, saltar mais longe, do que qualquer um já conseguira. Ai que surgem um João do Pulo (salto triplo), um Pelé (futebol), uma Maria Ester Bueno (tênis), um Ricardo Prado (nataçāo), um Joaquim Cruz (corrida).

Enquanto os atletas conseguem grande sucesso nesta batalha constante, muitos de nós já tem sorte apenas em conseguir andar com alguma pose, correr o suficientemente rápido para pegar o ônibus ou para dar alguns passos na última moda de dança.

O sucesso na realização em cada uma das atividades comuns, depende de quanto bem nós aprendemos a mover nossas estruturas dentro dos limites impostos pelas leis físicas que governam o movimento na atmosfera terrestre. Todos os seres humanos normais fisicamente, se movem basicamente da mesma maneira. Mas de indivíduo para indivíduo há muitas diferenças no estilo de se mover. Cada um de nós, assim que adquirimos equilibrio na posição ereta e exploramos o meio ambiente nos locomovendo nele, desenvolvemos nossa maneira característica e única de se mover.

Muitos fatôres influenciam essa característica de movimento. O primeiro é certamente, os pais que escolhemos. Nós herdamos deles, como eles de nossos avós, o tipo corporal que pode ou não facilitar nossa movimentação de forma eficiente. Nós também herdamos o sistema orgânico, o metabolismo, o sistema nervoso; todos eles com algum efeito na qualidade com que se movimenta. Além do mais, nosso comportamento no movimento é influenciado pelo ambiente em que nascemos, nāo apenas o ambiente físico na terra e localização geográfica, mas a familia, a vizinhança e muitos outros fatores sócio-culturais. Nossa maneira única de se mover é então um produto da interação entre nossa genética e nosso ambiente físico-social.

Todo movimento é proposital. Alguns propósitos sāo imediatos e identificáveis enquanto outros não são tão aparentes. Por exemplo: cada esporte requer uma maneira especifica de movimento; no tênis, o propósito imediato e óbvio dos movimentos é dirigir a bola sobre a rêde para o lado do oponente. Mas a propósito a longo prazo nāo é tāo aparente para nós. A pessoa pode estar pretendendo jogar profissionalmente, ou pode estar jogando por razōes sociais, ou ainda para "fazer exercício" De uma coisa podemos estar certos: que seus movimentos tem objetivos, mesmo que eles não coincidam com os nossos.

No começo da vida, o movimento ocorre como respostas motoras a estimulaçōes ambientais. Os movimentos dos bebês têm propósitos de satisfazer ou evitar a dor, fome, sêde, etc. Como crianças, adolescentes e adultos, temos outros propósitos para nos movimentar: satisfazer curiosidades, desenvolver habilidades motoras, expressar e comunicar idéias, emoções, informaçōes, etc. Alguns movimentos sāo usados com propósitos de sobrevivência, enquanto outros servem para brincar, recrear, ou alivar tensões. Há muitos botões para serem apertados, cabelos para serem penteados, sapatos para serem amarrados, camas para serem arrumadas, casas para serem varridas $e$ outras milhares de tarefas que requerem movimento do nosso corpo no espaço. 


\section{O MOVIMENTO NOS ESPORTES}

A musculatura humana é formada por mais de 400 músculos de diferentes formas e tamanhos e não existe um único movimento que seja executado por um músculo apenas. Todos nossos movimentos desenvolvem-se nas articulaçōes e vários músculos e, grupos musculares unem-se para um trabalho conjunto, sobretudo nos movimentos de um esportista. A unidade dos grupos musculares atuando em conjunto, é conhecida como CADEIAS CINÉTICAS OU CADEIAS MUSCULARES.

As cadeias cinéticas modificam-se de acordo com cada movimento e a tarefa de cada músculo é determinada pela função dos respectivos grupos musculares relacionados. Por isso não se pode julgar apenas os músculos que exercem uma ação sobre uma determinada articulação, porém deve-se considerar a totalidade dos músculos que estão numa cadeia, passando por numerosas articulaçōes. Assim, partes distantes do corpo são influenciadas através da cadeia de articulações, pela contração dos músculos.

Para se compreender corretamente o trabalho muscular no movimento esportivo, devese compreender não apenas o músculo isolado, mas a completa cadeia cinética que participa do movimento. As cadeias cinéticas e não apenas os músculos, passam pelas articulaçōes, devendo por isso serem entendidas em igual proporção para a execução ótima de um movimento. Deve-se ainda estar ciente que as cadeias cinéticas se modificam de acordo com o transcorrer de um movimento e que mesmo dentro de um movimento ocorre um jogo alternado constante de músculos sinergistas e antagonistas.

As cadeias cinéticas podem ser cadeias de extensāo e cadeias de freio. As cadeias de freio regulam a força da extensão e influenciam a duração temporária e a intensidade do movimento.

As cadeias musculares apresentadas em preto na Figura 1, corresponde aos grupos musculares cujas contrações levam a uma forte extensão nas articulaçōes do joelho e quadril. A cadeia de extensão alcança primeiramente as protuberâncias do calcanhar até a crista ilíaca. Pela ligação lombar o glúteo máximo experimenta uma extensão de sua área de função no músculo grande dorsal e liga-se como cadeia de extensão aos músculos dorsais mais profundos (eretor espinhal e transverso espinhal) terminando nos músculos da nuca.

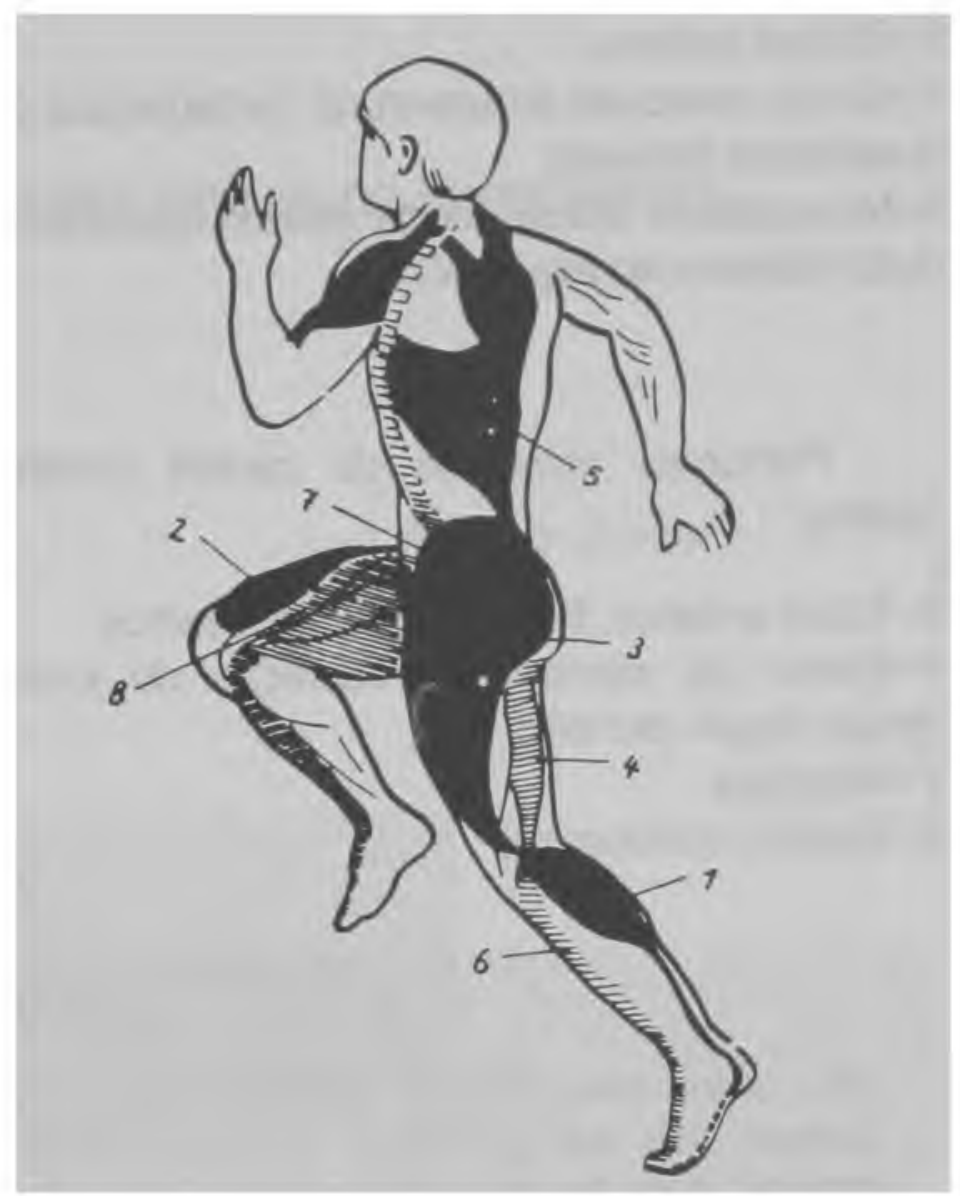

FIGURA 1: Cadeias musculares na corrida (Grosser, 1972)

Contudo esse movimento de extensão não pode ser executado ilimitadamente, ao extensor está contraposta uma cadeia de freios, que é assinalada de forma riscada na Figura 1. Enquanto que os flexores, em conjunto com as funçōes articulares determinadas, funcionam como "freio" para um movimento de extensão, os extensores da outra perna flexionada estão como "freio" dos flexores. A cadeia flexora consiste na musculatura que passa na parte anterior da perna, do grupo muscular isquio-crural, na parte posterior da coxa, seguindo sobre os adutores até a sínfise, para continuar funcionalmente no reto abdominal. A cadeia segue sobre a parte da fascia abdominal, do grande peitoral, até o esternocleidomastoideo e aos músculos escalenos.

A ótima execução do movimento e uma liberdade de oscilação das articulaçōes somente pode ocorrer, quando no movimento de maior tensão do agonista (por exemplo os extensores) os músculos antagonistas (no caso os flexores) se encontram numa ótima descontração ou soltura. 
Principais músculos da cadeia cinética extensora:

1-Gastrocnêmios

2-Quadriceps femural

3-Glúteo máximo

4-Grupo muscular isquio-crural (antagonista do quadriceps femural)

5-Musculatura dorsal longa (eretor espinhal) e curta (transverso espinhal). flexora:

Principais músculos da cadeia cinética

6-Tibial anterior, flexor longo dos artelhos

4-Flexor da perna na articulação do joelho (grupo isquio-crural)

7-lliopsoas

8-Sartório (costureiro)

\section{CONSEQÜÊNCIAS PARA O TREINAMENTO}

A musculatura esquelética humana contém cerca de 150 milhōes de fibras, onde cada fibra é especializada numa atividade, o que resulta num grande número de combinaçōes para as possibilidades de movimento. Pode-se então deduzir a necessidade imprescindivel do treinamento ter uma atuação sobre o caráter global do movimento, devendo por isso os exercicios empregados, principalmente os de força e de alongamento, serem o mais semelhante possivel ao movimento esportivo. Em outras palavras, os exercícios de força e de alongàmento devem ser executados de modo semeIhante à técnica do movimento esportivo. Não é suficiente levar em conta apenas os músculos que participam do movimento, deve-se considerar também sua ação articular, isto é, suas cadeias cinéticas.

\section{ABSTRACT}

This article describes the nature of human movement. We are constantly struggling against gravity. Many factors are involved in the formation of one $s$ movement behavior: heredity, the physical environment, and many other socio- cultural factors. In sports we need to understand the kinetic chains responsible for the execution of a particular athletic movement. This understanding brings as consequence some directions for training.

\section{REFERÊNCIAS BIBLIOGRÁFICAS}

BARBANTI, V. J. Treinamento Físico - Bases Científicas, São Paulo, 1986.

GROSSER, M. Die Zweckgymnastik des Leichtathleten. Stuttgart, 1972.
HAY J. G., REID, J. G. The anatomical and mechanical bases of human motion. Englewood Cliffs, 1982. 